\title{
Reduction of the Voltage Distortion with a Converter Employed as Shunt Harmonic Impedance
}

\author{
Wouter R. Ryckaert*, Koen De Gussemé*, David M. Van de Sype*, Jozef A. Ghijselen ${ }^{\dagger}$ and Jan A. Melkebeek* \\ * Ghent University, Faculty of Engineering, Department of Electrical Energy, Systems and Automation (EESA), \\ Electrical Energy Laboratory (EELAB), Sint-Pietersnieuwstraat 41, B-9000 Ghent, Belgium \\ E-mail: Wouter.Ryckaert@UGent.be \\ ${ }^{\dagger}$ Inverto N.V., J. Parijslaan 8, B-9940 Evergem, Belgium
}

\begin{abstract}
The amount of non-linear and unbalanced loads (such as adjustable speed drives and PC's) connected to the electric power system is steadily growing. The power quality i.e. the reliability of the energy supply and the quality of the voltage waveform, may be severely degraded and may cause many unfavourable effects on both the power system and the connected loads. Especially in the case of resonances, severe voltage distortion may result.

Although complete compensation is only possible using true active filters, resistive shunt harmonic impedances (SHI) have been shown to provide a considerable reduction of the harmonic propagation. These impedances can be implemented using active power electronic devices and are controlled to synthesize a resistive load. Benefits: no need to measure the polluting load current, effective for all harmonics and different resonance conditions, simple control strategy, and may be implemented as a secondary control function of an active power supply.

In this paper, a practical implementation of a resistive SHI is proposed. A new control strategy for a boost power factor correction (PFC) converter has been implemented in order to achieve a programmable resistive input impedance for harmonics, independent of the input impedance for the fundamental component. Furthermore, the potential to damp a resonance in a power distribution system is demonstrated using an experimental setup.
\end{abstract}

\section{INTRODUCTION}

The increasing use of harmonic polluting loads causes harmonic voltage distortion that may propagate throughout the distribution system. It is well known that voltage waveform distortion may adversely affect the equipment connected to the power system [1], [2]. In particular, harmonic resonance phenomena in power systems are known to cause severe voltage distortion [3], and even failure of power system components.

In the last decades, power quality improvement has become an important target for both the designer of electric loads and the energy provider. When designing an electric load, it is important to consider its influence on the power quality of the power system. A load behaving favourably for the electric power system should not deteriorate the voltage waveform, but instead, should contribute to the reduction of the power system pollution. When the parameters of the power system and the behaviour and location of the polluting loads are known (or estimated from voltage and current measurements), the quality of the voltage waveform can be optimized throughout the power system by implementing an appropriate behaviour of the favourable loads [4]-[6]. In most cases, however, the parameters of the power system and its sources of pollution are unknown and time varying. Hence, the approach presented in [4]-[6] is only plausible in particular applications and generally leads to complicated algorithms.

However, very little information is needed when the load behaves as a (controlled) impedance, as only the power system voltage at the load terminals is required. Although this limits the amount of voltage waveform improvement that can be obtained, significant improvement is feasible, especially if the power system is subjected to resonances [7]-[11].

This paper begins with a general description of a practical load which behaves as a controlled impedance for harmonics. Afterwards, a control strategy for a resistive shunt harmonic impedance is proposed. This control strategy is implemented in a single-phase boost power factor correction converter. Furthermore, the potential to damp a resonance in a power distribution system is demonstrated using an experimental setup. The damping performance is independent of the output power level of the converter and is compared with a converter drawing a pure sinusoidal current.

\section{Shunt Harmonic IMPEDANCE}

It was shown [10] that a controlled impedance which remains effective to mitigate the harmonic pollution in the case of unknown and varying power system impedances and resonance conditions, should have a resistive behaviour for all harmonics. Although complete harmonic compensation is only possible using true active filters [12], it has been shown [9]-[11], [13], [14] that shunt active compensators, behaving as linear resistive shunt harmonic impedances (SHI) for harmonics, can provide a considerable reduction of the harmonic propagation throughout a distribution feeder. A good choice to install a resistive SHI is near the end of the feeder [15], which confirms the proposition suggested by Akagi [9], [13], [16] to place an active line terminator on the distribution feeder with a resistive impedance behaviour for harmonics.

The resistive impedance function can be implemented as the control objective of an active (power electronic) compensator [8], [9], [13], [16] or as a secondary function of an active power supply [2], [7], [11], [17], [18]. This may be achieved by proper design of the control strategy. Because of the simplicity of the resistive SHI control strategy, many power electronic loads can be equipped with it and can be 


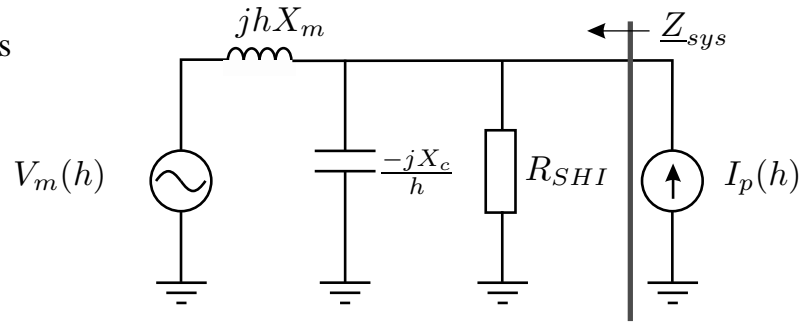

Fig. 1. Parallel resonance

spread throughout the distribution system. In this way, every optimised load contributes to the reduction of the harmonic pollution in the entire distribution system.

Consider the power system of Fig. 1. Without $R_{S H I}$, an undamped parallel resonance condition is fulfilled at the harmonic order $h_{r}=\sqrt{X_{c} / X m}$. A resistive SHI, modelled as a true resistance $R_{S H I}$ in Fig. 1, becomes very important to damp the system resonance. At the resonance frequency $f_{r}$, the power system impedance as seen by the (polluting) current source $I_{p}$, becomes $\left|\underline{Z}_{s y s}\left(f_{r}\right)\right|=R_{S H I}$, rather than $\left|\underline{Z}_{\text {sys }}\left(f_{r}\right)\right|=\infty$, when no SHI is used. Therefore, a higher amount of loads with a resistive behaviour for harmonics results in a lower impedance near the parallel resonance (such as with a parallel connection of resistors), and thus in a lower harmonic voltage component at the resonance frequency.

The idea to install resistive SHI's to mitigate harmonic pollution originates from the virtual resistor concept (or active damping concept) to avoid possible instability in the control loop of LC(L)-filtered active rectifiers [19]-[21].

It has to be emphasized that a practical resistive SHI should not be a physical resistance as in Fig. 1 but should be implemented as a (power electronic) converter with a resistive behaviour for harmonics (in steady state). The absorbed harmonic active power can be seen as useful to compensate (a part of) the losses of the converter or to be transferred to the output of the converter. Hence, the absorbed harmonic active power does not lead to ohmic losses and dissipation (as in a resistor), but is applied usefully.

\section{Control Strategy FOR A RESISTIVE ShUnT HARMONIC IMPEDANCE}

The implementation of a resistive SHI as a secondary control function of a power electronic load will be explained. A control strategy for a practical resistive SHI is shown in Fig. 2. The input filter of the converter consists of $C_{i n}$ and $L_{i n}$ and is necessary to filter the high frequency components due to the switching process. It is assumed that the ac-dc converter contains a fast current-control loop that allows fast tracking of the desired input current, or $i_{S H I} \simeq i_{S H I}^{*}$.

The most recent control strategies are designed to shape the input current proportional to the input voltage, thus obtaining a resistive behaviour at the input of the converter [17], [22]. As mentioned before, this control strategy is more interesting with regard to the stability of the supplying grid, as compared to converters with a pure sinusoidal input current waveform, because converters with resistive input behaviour mitigate the proliferation of harmonics in the case of a distorted grid voltage.

The regular current-control loop for a resistive SHI with a constant value for all frequencies (including the fundamental component), is shown in the rectangle of Fig. 2 (without the dashed lines). The desired input current $i_{S H I}^{*}$, and hence the real input current, are proportional to the input voltage $v_{S H I}$ with ratio $g_{h}$. In this manner, the converter has a resistive input impedance with a constant value for all frequencies; the resistive value is determined by the desired output power level and equals $1 / g_{h}$. The output power level is controlled to its desired value by the voltage-control loop, which is typically 10 times slower than the current-control loop. The voltage-control loop controls the output voltage $v_{o}$ to its desired output voltage $v_{o}^{*}$. The variable $g_{h}$ is the emulated conductance at the input of the boost PFC converter [17], [22].

In this paper, this control strategy is extended in such a way that the converter has a constant resistive value for all harmonics except for the fundamental component. For the fundamental component, the converter still behaves resistively but the conductance has a value which is dependent on the desired output power level. In this manner, a novel practical implementation for a SHI is developed: the SHI has a different resistive impedance for the fundamental component than for harmonics. Hence, it becomes possible for the converter to preserve its damping potential for a wide range of converter power levels, whereas with a traditional resistive input current behaviour, the damping potential decreases with the input power of the converter.

A comparable control strategy is also introduced by [11] for three phase ac-dc converters. Nevertheless, this control strategy (using the $p-q$ transformation) is not (easily) applicable to single-phase converters (low power applications), so the new control strategy proposed in this paper is based upon the control of [17], [23].

To obtain a different conductance for harmonic components and the fundamental component, the full control scheme of Fig. 2 is applied (including the dashed lines). To obtain the different conductances, $\Delta i_{S H I, 1}^{*}$ is subtracted from $\sum_{h} i_{S H I, h}^{*}=g_{h} \cdot v_{S H I}$. The component $\Delta i_{S H I, 1}^{*}$ has to be in phase with $v_{S H I}$ (using e.g. a Phase Locked Loop). The value of $\Delta i_{S H I, 1}^{*}$ equals $g^{\prime} \cdot V_{S H I, 1} \sin (\omega t)\left(V_{S H I, 1}\right.$ is the amplitude of the fundamental component of $\left.V_{S H I}\right)$. It is easily verified that the conductance for the fundamental component will be $g_{1}=g_{h}-g^{\prime}$. When $g^{\prime} \leq g_{h}$, the converter absorbs fundamental power from the power system. However, when $g^{\prime} \geq g_{h}$, the converters delivers fundamental power to the power system, while the damping feature for harmonics remains. This can be useful for converters applied in distributed generation (e.g. solar energy). In this way, a converter with a positive harmonic input conductance and a negative fundamental input conductance is obtained. Hence, the harmonic mitigation potential is maintained. This is not the case for converters with a constant resistive conductance for all harmonics (defined by the output power level). In that case, 


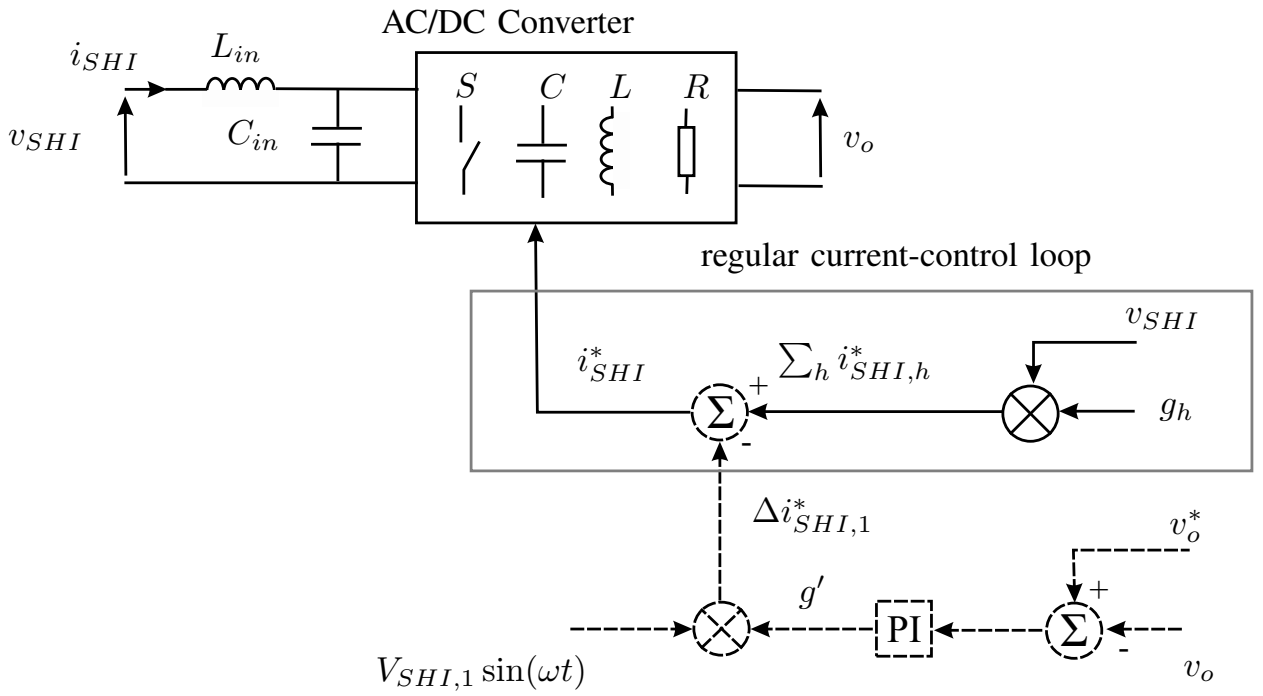

Fig. 2. Control strategy for a resistive SHI

the conductance for harmonics is also negative (re-generation mode) and can lead to instability or tripping of the converter [3].

When $g^{\prime}=g_{h}$, the converter absorbs (nearly) no fundamental power and behaves as a pure 'damper' which can be installed by electric utilities to improve the overall power quality (such as [8], [9], [13], [16]).

\section{EXPERIMENTAL RESULTS}

\section{A. Practical implementation}

In this section, the damping performance of a resistive SHI is demonstrated by using a prototype of a single-phase digitally controlled boost Power Factor Correction (PFC) converter, as shown inside the rectangle of Fig. 3. Because a diodebridge is used at the input, the converter is not able to deliver fundamental power to the distribution system. However, it would be possible with a full bridge boost converter.

The current-control loop with duty-ratio feed-forward proposed in [17], [23] that emulates a resistive input impedance for a wide frequency-range, is adapted in such a way that the converter has a constant resistive value for all harmonics except for the fundamental component (see section III). For the fundamental component, the converter still behaves like a resistance but this value is determined by the desired output power level (through the output voltage controller).

For the experimental verification of the control algorithm a $1 \mathrm{~kW}$ boost PFC converter is employed. The converter has an input capacitor of $470 \mathrm{nF}$, an inductor of $1 \mathrm{mH}$, and an output capacitor of $470 \mu \mathrm{F}$. The switches are MOSFET SPP20N60S5 and diode RURP3060. The converter is supplied from a linear amplifier (PAS1000 of Spitzenberger \& Spieß). In normal operating conditions, the input voltage is $230 \mathrm{~V}, 50 \mathrm{~Hz}$, while the output voltage is programmed to be $400 \mathrm{~V}$. The converter is controlled by the ADMC401 digital signal processor of Analog Devices. The sampling of the input current and input voltage is synchronized with the switching of the converter, at $50 \mathrm{kHz}$,
TABLE I

IMPEDANCE BEHAVIOUR

\begin{tabular}{|c|c|c|c|c|}
\hline$h$ & $V_{P C C}(h)$ & $I_{S H I}(h)$ & $\left|Z_{i n}\right|[\Omega]$ & $\angle Z\left[^{\circ}\right]$ \\
\hline 1 & $228.2 \mathrm{~V}$ & $2.01 \mathrm{~A}$ & 113.4 & -2.5 \\
5 & $9.9 \%$ & $27.1 \%$ & 41.3 & 6 \\
7 & $4.9 \%$ & $14.5 \%$ & 38.7 & 1.4 \\
11 & $4.9 \%$ & $12.9 \%$ & 42.9 & 24.2 \\
\hline
\end{tabular}

while the sampling of the output voltage is performed at $1 \mathrm{kHz}$. For a more detailed description of the digital implementation of the current- and voltage-loop of the practical SHI, the reader is referred to [18].

In Fig. 4, the input current of the SHI $i_{S H I}$ is shown when a distorted input voltage $v_{P C C}$ is applied to the boost PFC converter (using the programmable power source). The voltage is distorted with a 5-th, 7-th and 11-th harmonic component as mentioned in Table I. As shown in Table I, the impedance for harmonics is nearly constant and differs from the value of the fundamental component (with a factor 2.75 for an output power level $P_{\text {out }}=484 \mathrm{~W}$ ). As the phase angle of the total impedance is small, the input impedance is resistive. For higher harmonic components $(\geq 9)$, the influence of the input filter inductance $L_{i n}$ becomes visible (a lagging input current).

\section{B. Damping performance}

The damping performance of the practical SHI is demonstrated on a scale model of a typical distribution feeder as shown in Fig. 3. The power system is represented by its sinusoidal mains voltage $V_{m}$ and its internal impedance $\omega L_{m}$, which is dominated by the short-circuit impedance of the distribution system. The non-linear loads are concentrated in the point-of-common-coupling (PCC), and are capacitively smoothed diode bridge rectifiers with an input filter impedance $\omega L_{N L}$. In the practical setup, typical values found in practice are used: $\omega \cdot L_{m}=4.47 \%, \omega \cdot L_{N L}=4.0 \%$. All values are 


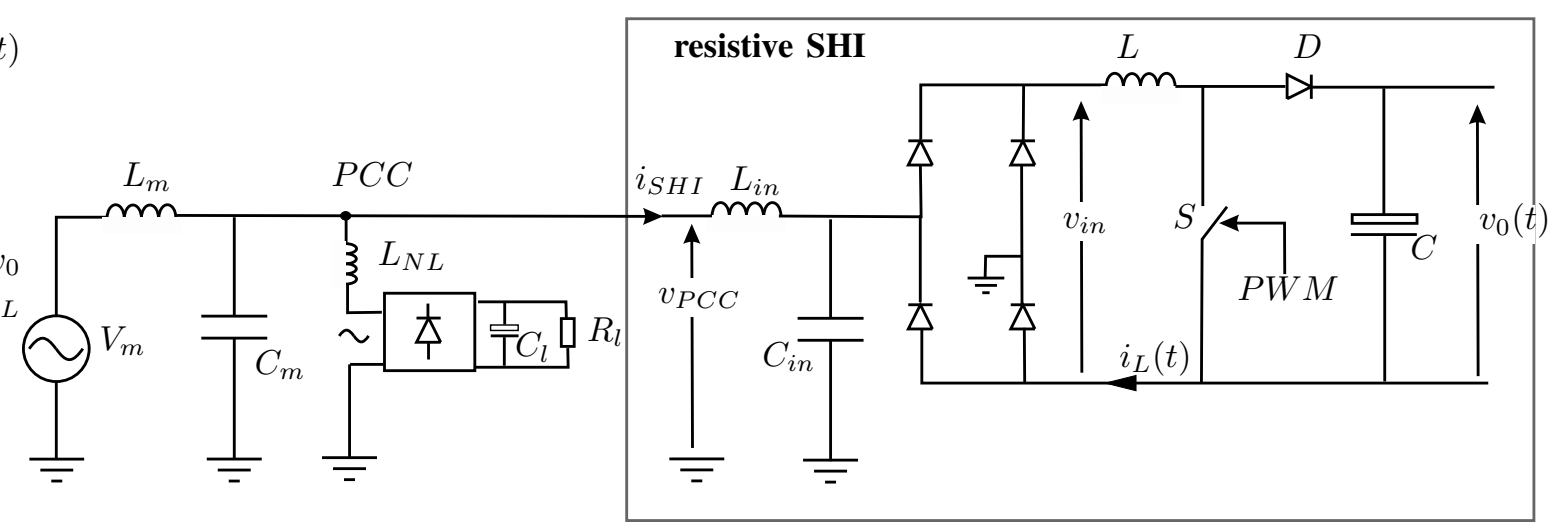

Fig. 3. Distribution system

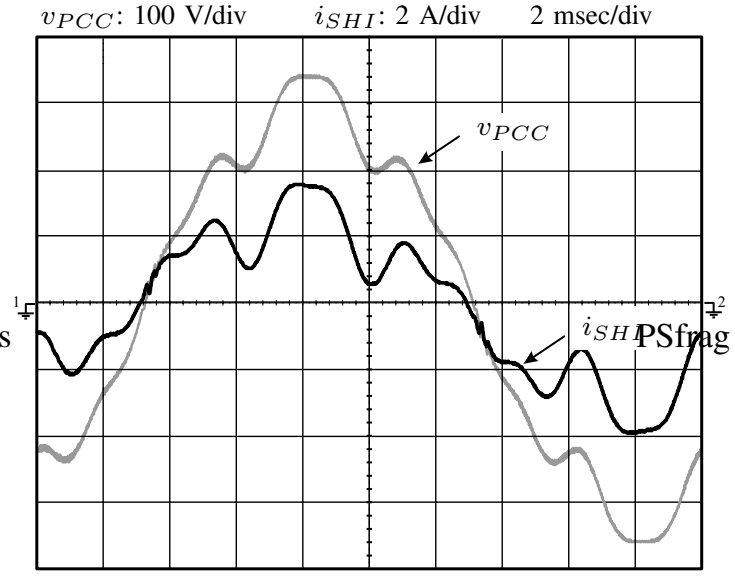

Fig. 4. Input voltage $v_{P C C}$ and input current $i_{S H I} ; P_{\text {out }}=484 \mathrm{~W}$; input voltage distortion: 5 -th: $10 \%$; 7-th: $5 \%$; 11-th: $5 \%$

referred to the total apparent power of the distribution system (in this case $S_{R E F}=1200 \mathrm{VA}$ and the reference voltage $V_{R E F}=230 \mathrm{~V}$ ). The total non-linear load level $p_{N L}$ is $15 \%$.

The capacitor $C_{m}$ represents the power factor correction capacitor banks. In the next experiments, the capacitor $C_{m}$ is tuned to get a resonance at the 9-th harmonic, resulting in a severe voltage distortion at the PCC as shown in Fig. 5. In the same figure, the capacitor current $i_{C}$ is also shown. The resonance at the 9-th harmonic component is clearly visible. In Table II, the harmonic decomposition of the PCC voltage displays a maximum at the 9-th harmonic component (5.22\%). The resulting Total Harmonic Distortion $\left(T H D_{V}\right)$ of the voltage at the PCC is $6.5 \%$. To mitigate this voltage distortion, the boost PFC converter with the proposed SHI current-control loop is connected at the PCC. In Fig. 6, 7, and 8, the voltage at the PCC $v_{P C C}$ and the input current of the SHI $i_{S H I}$ are shown for 3 different SHI output power levels $(253 \mathrm{~W}, 510 \mathrm{~W}$, and $750 \mathrm{~W}$ respectively). The damping performance is clearly shown in Tabel III. The voltage THD at the PCC is reduced with about $50 \%$ to $3.2 \%$ for a resistive impedance value for harmonics $1 / g_{h}$ of $1 \mathrm{pu}$. As expected, the resulting $T H D_{V^{-}}$ values are almost independent of the output power level of

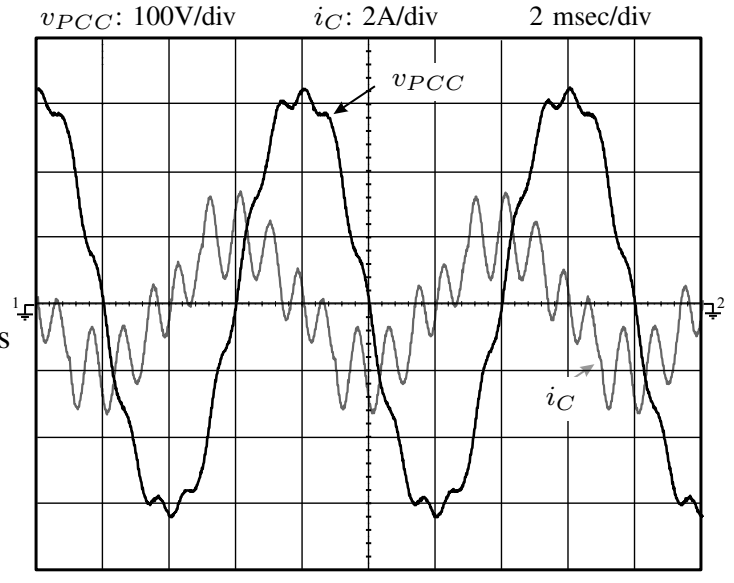

Fig. 5. $\quad v_{P C C}$ and $i_{C}$ when no SHI is installed

TABLE II

$V_{P C C}(h)$ WHEN NO SHI IS INSTALLED

\begin{tabular}{|c|c|}
\hline$h$ & $V_{P C C}$ \\
\hline 1 & $232.2 \mathrm{~V}$ \\
3 & $1.68 \%$ \\
5 & $2.11 \%$ \\
7 & $2.73 \%$ \\
9 & $\mathbf{5 . 2 2} \%$ \\
11 & $0.61 \%$ \\
13 & $0.57 \%$ \\
15 & $0.24 \%$ \\
17 & $0.10 \%$ \\
19 & $0.10 \%$ \\
21 & $0.04 \%$ \\
\hline
\end{tabular}

the PFC converter. Only for low power levels (300 W or lower), there is a small difference between the measured value and the predicted value of the current $i_{S H I}$. The reason is that the converter behaviour differs from the ideal behaviour when the boost PFC converter is operating in discontinuous conduction mode for low power levels [17]. However, the damping performance remains virtually unaffected (Fig. 6, Table III). 


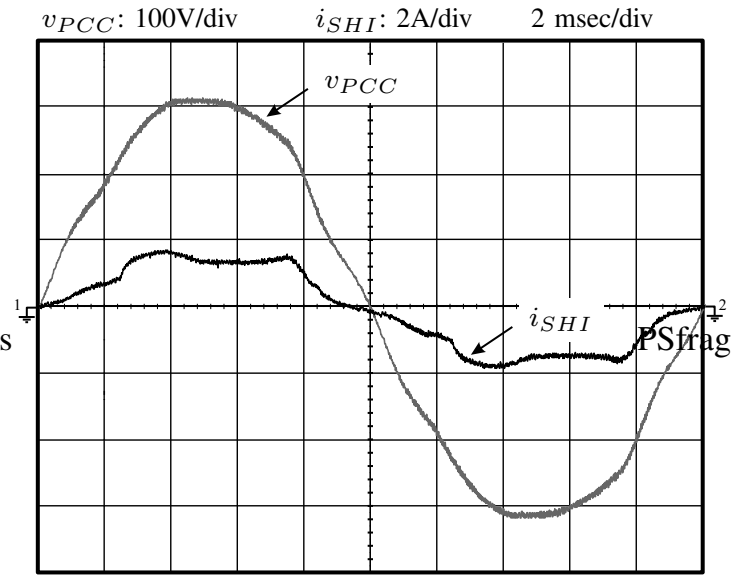

Fig. 6. $\quad v_{P C C}$ and $i_{S H I}$ for $P_{\text {out }}=253 \mathrm{~W}$

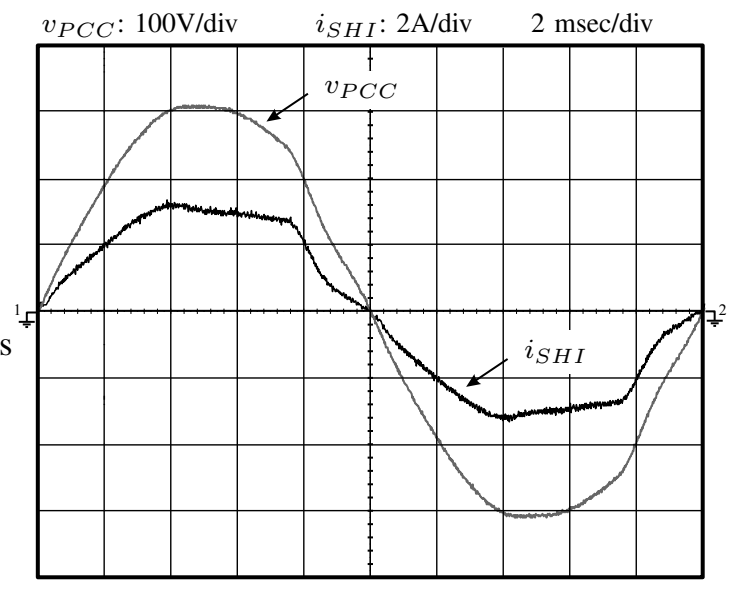

Fig. 7. $v_{P C C}$ and $i_{S H I}$ for $P_{\text {out }}=510 \mathrm{~W}$

\section{Resistive input behaviour with constant resistive value $\forall h$}

The damping performance of the proposed control strategy is compared with the damping performance of the 'classical' resistive boost PFC converter. Therefore, the regular current control loop of Fig. 2 is used. In this case, the conductance for the fundamental component equals the conductance for harmonics and is dependent on the desired output power level.

In Table IV, the damping performance of the boost PFC converter is shown for the same output power levels as in section IV-B. Because the damping performance is dependent on the output power level, large $T H D_{V}$-values may occur at light load (e.g. $253 \mathrm{~W}$ ), due to the slightly damped resonance.

The input current $i_{\text {conv }}$ has the same waveform as the input voltage $v_{P C C}$ because of the constant resistive value for all harmonics. This is shown in Fig. 9 for an output power level of $510 \mathrm{~W}$ (compare Fig. 9 with Fig. 7).

TABLE III

$T H D_{V}(P C C)$ VALUES FOR DIFFERENT SHI POWER LEVELS

\begin{tabular}{|c|c|c|c|c|}
\hline & without SHI & $253 \mathrm{~W}$ & $510 \mathrm{~W}$ & $705 \mathrm{~W}$ \\
\hline$T H D_{V}(P C C)$ & $6.5 \%$ & $3.7 \%$ & $3.2 \%$ & $3.2 \%$ \\
\hline
\end{tabular}

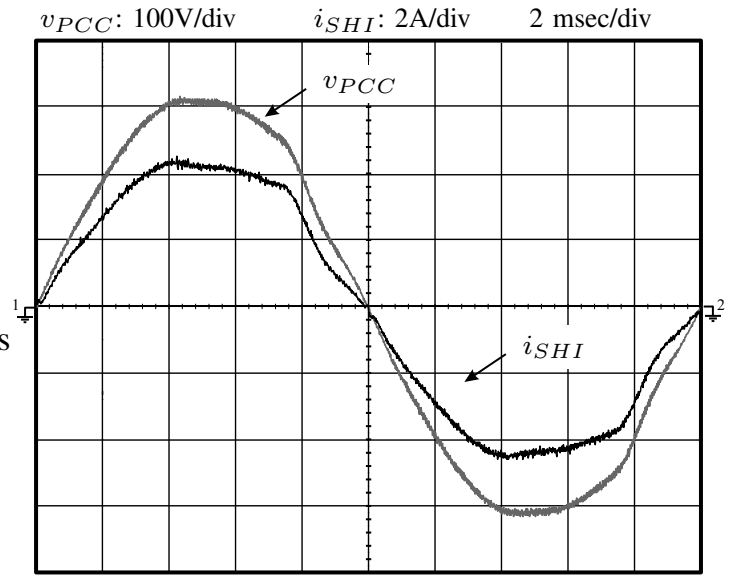

Fig. 8. $\quad v_{P C C}$ and $i_{S H I}$ for $P_{\text {out }}=705 \mathrm{~W}$

TABLE IV

$T H D_{V}(P C C)$ VALUES FOR A RESISTIVE PFC CONVERTER WITH CONSTANT RESISTIVE VALUE $\forall h$

\begin{tabular}{|c|c|c|c|c|}
\hline & without SHI & $253 \mathrm{~W}$ & $510 \mathrm{~W}$ & $705 \mathrm{~W}$ \\
\hline$T H D_{V}(P C C)$ & $6.5 \%$ & $5.7 \%$ & $4.1 \%$ & $3.7 \%$ \\
\hline
\end{tabular}

\section{Sinusoidal input current}

When the emulated conductance for harmonics is adjusted to zero $\left(g_{h}=0\right)$, the boost PFC converter draws a sinusoidal input current, even when the mains voltage is polluted. Hence, the damping performance disappears. The voltage at the PCC $\left(v_{P C C}\right)$ and the input converter current $\left(i_{\text {conv }}\right)$ are shown in Fig. 10 for an output power level of $516 \mathrm{~W}$. The other system parameters remain the same as in section IV-B.

Because the resonance remains undamped, the resulting $T H D_{V}$ at the PCC is $6.4 \%$.

From this example, it is clear that loads with a constant resistive value for harmonics can provide a considerable damping of system resonances in contrast to loads drawing a pure sinusoidal current.

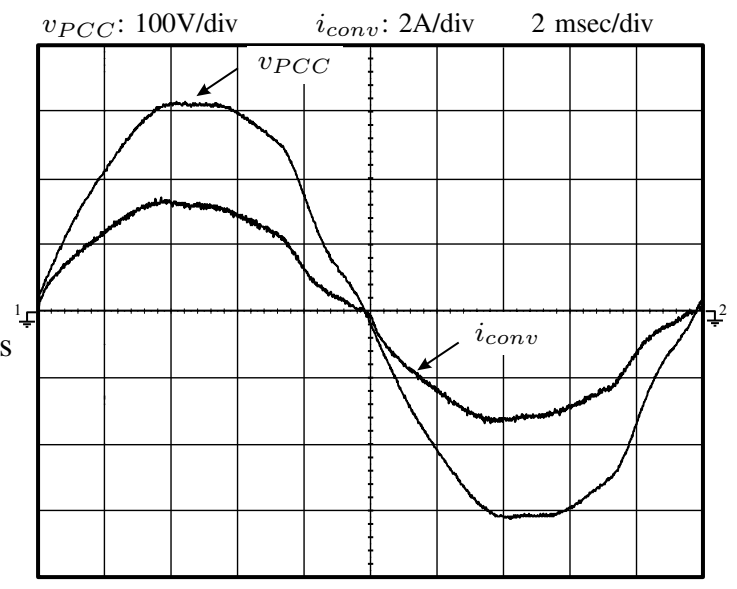

Fig. 9. $v_{P C C}$ and $i_{c o n v}$; resistive $\mathrm{PFC}$ converter with constant resistive value $\forall h ; P_{\text {out }}=510 \mathrm{~W}$ 


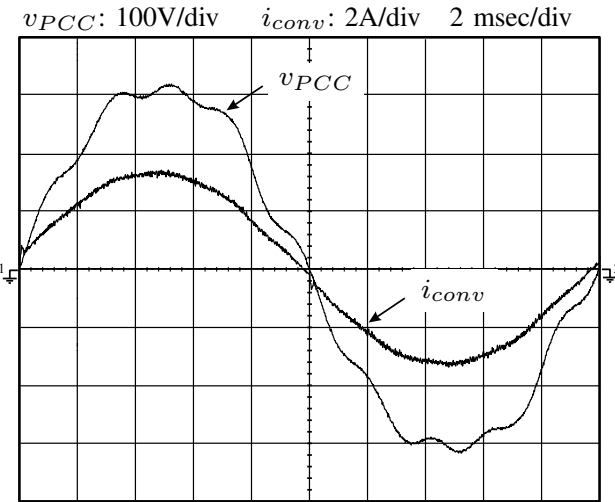

Fig. 10. $v_{P C C}$ and $i_{c o n v}$; PFC converter with sinusoidal input current; $P_{\text {out }}=510 \mathrm{~W}$

\section{CONCLUSiOnS}

To improve power quality, it is important to design electrical loads behaving favourably for the electric power system. A load with a resistive behaviour for harmonics contributes to the reduction of the power system pollution and consequently, has a favourable influence on the power quality.

In this paper, a novel current-control loop is implemented for a converter with a resistive input impedance. The converter has a constant resistive value for all harmonics except for the fundamental component. For the fundamental component, the converter still behaves resistively but the resistive value is determined by the desired output power level.

In this manner, the damping performance of the converter becomes independent of the output power level. This control strategy is implemented in a digitally controlled boost PFC converter. The damping performance of this converter is demonstrated on a scale model of a distribution system with a parallel resonance. The reduction of the voltage THD at the PCC is remarkable (about $50 \%$ with a 1 pu resistive value for harmonics) and is nearly independent of the output power level of the converter.

If many power electronic loads are equipped with this control strategy and spread throughout the distribution system, the harmonic pollution will be reduced and a lot of power quality problems will be avoided. Moreover, no extra intervention of the installer is required, even when the structure of the power system changes, which is an important part of the flexibility of the proposed control strategy.

\section{ACKNOWLEDGEMENTS}

The research of Wouter Ryckaert is supported by the Institute for the Promotion of Innovation through Science and Technology in Flanders (IWT-Vlaanderen).

\section{REFERENCES}

[1] IEEE Task Force on the effect of harmonics on equipment, "Effects of harmonics on equipment," IEEE Transactions on Power Delivery, Vol. 8, No. 2, Apr. 1993, pp. 672-680.

[2] M.H.J. Bollen, "What is power quality?," Electric Power Systems Research, Vol. 66, No. 1, Jul. 2003, pp. 5-14.

[3] J.H.R. Enslin, and P.J.M. Heskes, "Harmonic interaction between a large number of distributed power inverters and the distribution network," IEEE Transactions on Power Electronics, Vol. 19, No. 6, Nov. 2004, pp. 1586-1593.
[4] X. Dai, and R. Gretsch, "Optimal compensator currents for the reduction of the harmonic distortion in networks," European Transactions on Electrical Power, Vol. 4, No. 4, Jul. 1994, pp. 301-313.

[5] W.K. Chang, and W.M. Grady, "Minimizing harmonic voltage distortion with multiple current-constrained active power line conditioners," IEEE Transactions on Power Delivery, Vol. 12, No. 2, Apr. 1997, pp. 837-843.

[6] A.E. Emanuel, and M. Yang, "On the harmonic compensation in nonsinusoidal systems," IEEE Transactions on Power Delivery, Vol. 8, No. 1, Jan. 1993, pp. 393-399.

[7] Y. Sato, and T. Kataoka, "A current-type PWM rectifier with active damping function," IEEE Transactions on Industry Applications, Vol. 32 No. 3, May. 1996, pp. 533-541.

[8] T-N. Lê, M. Pereira, K. Renz, G. Vaupel, "Active damping of resonances in power systems," IEEE Transactions on Power Delivery, Vol. 9, No. 2, Apr. 1994, pp. 1001-1008.

[9] H. Akagi, "New trends in active filters for power conditioning," IEEE Transactions on Industry Applications, Vol. 36, No. 6, Nov. 1996, p.1312-1322.

[10] W.R.A. Ryckaert, J.A.L. Ghijselen, and J.A.A. Melkebeek, "Harmonic mitigation potential of shunt harmonic impedances," Electric Power Systems Research, Vol. 65, No. 1, Apr. 2003, p.63-69.

[11] T. Takeshita, and N. Matsui, "Current waveform control of PWM converter system for harmonic suppression on distribution system," IEEE Transactions on Industrial Electronics, Vol. 50, No. 6, Dec. 2004, pp. 1134-1139.

[12] B. Singh, K. Al-Haddad, and A. Chandra, "A review of active filters for power quality improvement," IEEE Transactions on Industrial Electronics, Vol. 46, No. 5, Oct. 1999, pp. 960-971.

[13] P. Jintakosonwit, H. Fujita, and H. Akagi, "Control and performance of a fully-digital-controlled shunt active filter for installation on a power distribution system," IEEE Transactions on Power Electronics, Vol. 17, No. 1, Jan. 2002, pp. 132-140.

[14] M. Saito, T. Takeshita, and N. Matsui, "Modeling and harmonic suppression for power distribution systems," IEEE Transactions on Industrial Electronics, Vol. 50, No. 6, Dec. 2003, pp. 1148-1158.

[15] W.R.A. Ryckaert, J.A.L. Ghijselen, J.J.M. Desmet, A.P.M. Van den Bossche, J.A.A. Melkebeek, and D.M. Van de Sype, "The location of a resistive shunt harmonic impedance along a distribution feeder and its influence on hamonic propagation," has been accepted for publication in Electrical Engineering (Springer).

[16] H. Akagi, H. Fujita, and K. Wada, "A shunt active filter based on voltage detection for harmonic termination of a radial power distribution line," IEEE Transactions on Industry Applications, Vol. 35, No. 3, May 1999, pp. 638-645.

[17] D.M. Van de Sype, K. De Gussemé, A.P. Van den Bossche, and J.A. Melkebeek, "Duty-ratio feedforward for digitally controlled boost PFC converters," Proc. IEEE-Applied Power Electronics Conference (APEC 2003), Miami, USA, Feb. 2003, pp. 396-402.

[18] K. De Gussemé, W.R. Ryckaert, D.M. Van de Sype, J.A. Ghijselen, and J.A. Melkebeek, "A boost PFC converter with programmable harmonic resistance," accepted for publication at the IEEE-Applied Power Electronics Conference (APEC 2005),, Austin, TX, USA, Mar. 2005.

[19] V. Blasko, and V. Kaura, "A novel control to actively damp resonance in input LC filter of a three-phase voltage source converter," IEEE Transactions on Industry Applications, Vol. 33, No. 2, Mar. 1997, pp. 542-550.

[20] M. Liserre, A. Dell'Aquila, and F. Blaabjerg, "Genetic algorithmbased disign of the active damping for an LCL-filter three-phase active rectifier," IEEE Transactions on Power Electronics, Vol. 19, No. 1, Jan. 2004, pp. 76-86.

[21] P.A. Dahono, "A Control method to damp oscillation in the input LC filter of AC-DC PWM converters," Proc. IEEE Power Electronics Specialists Conference (PESC 2002), Cairns, Australia, June. 2002, Vol. 4, pp. 1630-1635.

[22] S. Ben-Yaakov, and I. Zeltser, "The dynamics of a PWM boost converter with resistive input," IEEE Transactions on Industrial Electronics, Vol. 46, No. 3, Jun. 1999, pp. 613-619.

[23] K. De Gussemé, D.M. Van de Sype, A.P. Van den Bossche, and J.A. Melkebeek, "Digital Control of Boost PFC Converters Operated in both Continuous and Discontinuous Conduction Mode," Proc. IEEE Power Electronics Specialists Conference (PESC 2004), Aachen, Germany, Jun. 2004, pp. 2346-2352. 